\title{
QUANTIFICAÇÃO DE BIOMASSA E GERAÇÃO DE CERTIFICADOS DE EMISSÕES REDUZIDAS NO CONSÓRCIO SERINGUEIRA-CACAU ${ }^{1}$
}

\author{
Michele Karina Cotta ${ }^{2}$, Laércio Antônio Gonçalves Jacovine ${ }^{3}$, Haroldo Nogueira de Paiva ${ }^{3}$, Carlos Pedro
} Boechat Soares ${ }^{3}$, Adonias de Castro Virgens Filho ${ }^{4}$ e Sebastião Renato Valverde ${ }^{3}$

\begin{abstract}
RESUMO - Os objetivos deste trabalho foram quantificar a biomassa vegetal e analisar o potencial de geração de Certificados de Emissões Reduzidas (CERs) em um consórcio de seringueira (Hevea brasiliensis) M. Arg. aos 34 anos de idade com cacaueiro (Theobroma cacao L.) aos 6 anos de idade. O experimento foi realizado nas Fazendas Reunidas Vale do Juliana, em Igrapiúna, Bahia. A quantificação da biomassa arbórea foi feita utilizando-se o método direto e destrutivo de cinco seringueiras e 10 cacaueiros, selecionados em uma área de 2,2 ha. A biomassa da serapilheira foi quantificada por meio da coleta do material sobre o solo. O estoque de carbono no consórcio seringueira-cacau foi de 91,5 $\mathrm{Mg} \mathrm{Cha}^{-1}$. Desse total, 84,7 $\mathrm{Mg} \mathrm{C} \mathrm{ha}^{-1}$ estavam estocados na seringueira, 5,2 $\mathrm{Mg} \mathrm{C}^{-1}$ no cacaueiro e $1,6 \mathrm{Mg} \mathrm{C}^{-1}$ na serapilheira. O carbono contabilizado no consórcio correspondeu a $336 \mathrm{Mg} \mathrm{CO}_{2 \text { eq. }}$ ha $^{-1}$, que equivalem à geração de $336 \mathrm{CERs} \mathrm{ha}^{-1}$. O consórcio seringueira-cacau apresentou capacidade para estocagem de carbono, podendo trazer grandes contribuições para a redução dos gases de efeito estufa na atmosfera, e isso o credencia como atividade promissora na geração de projetos candidatos ao recebimento de créditos de carbono.
\end{abstract}

Palavras-chave: Biomassa, créditos de carbono, Hevea brasiliensis e Theobroma cacao.

\section{BIOMASS QUANTIFICATION AND EMISSION REDUCTION CERTIFICATES FOR RUBBER - COCOA INTERCROPPING}

\begin{abstract}
The objective of this work were to quantify plant biomass and analyze the potential for generating Emission Reduction Certificates (ERCs) of 34-year-old rubber trees (Hevea brasiliensis M.Arg) intercropped with 6-year-old cacao (Theobroma cacao L.). The experiment was conducted on the farms Fazendas Reunidas Vale do Juliana, Igrapiúna, BA. Tree biomass quantification was carried out using the direct destructive method by harvesting five rubber trees and ten cocoa trees, in an area of 2.2 ha. Litter biomass was quantified by collecting material from the ground. Total carbon storage in rubber - cacao intercropping was $91.5 \mathrm{MgC}$

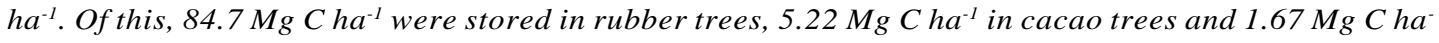
${ }^{1}$ in the litter. The amount of carbon found in the intercropping corresponds to $336 \mathrm{Mg} \mathrm{CO}_{2 e q}$. ha ${ }^{-1}$, equivalent to $336 \mathrm{CERs} \mathrm{ha}^{-1}$. The rubber-cacao intercropping has carbon stock capacity, and can greatly contribute to the reduction of the greenhouse effect gases, being a promising activity to generate programs to obtain carbon credits.
\end{abstract}

Keywords: Biomass, carbon credits, Hevea brasiliensis and Theobroma cacao.

\footnotetext{
${ }^{1}$ Recebido em 16.02.2007 e aceito para publicação em 22.08.2008.

${ }_{2}^{2}$ Programa de Pós-Graduação em Ciência Florestal da Universidade Federal de Viçosa (UFV). E-mail: <mkcotta@ yahoo.com.br>.

${ }^{3}$ Departamento de Engenharia Florestal da UFV. E-mail: <jacovine@ ufv.br>.

${ }^{4}$ Comissão Executiva do Plano da Lavoura Cacaueira - Centro de Pesquisas do Cacau (Ceplac/Cepec) Rodovia Ilhéus-Itabuna, Km 22, Ilheus, BA.
} 


\section{INTRODUÇÃO}

Nos últimos anos, a humanidade vem sendo alertada sobre um sério problema ambiental, o aquecimento global. A principal causa desse fenômeno tem sido atribuída ao aumento da concentração de determinados gases na atmosfera terrestre, os chamados Gases de Efeito Estufa (GEEs). Segundo Apps et al. (1999), as principais fontes antropogênicas dos GEEs estão associadas às mudanças de uso da terra, à queima de combustíveis fósseis e às atividades industriais.

A redução das emissões de GEEs é uma das metas do Protocolo de Kyoto, que determina que os países de economia desenvolvida adotem medidas de redução das emissões, entre 2008 e 2012, para um nível 5,2\% inferior ao registrado em 1990. O Protocolo de Kyoto previu também a utilização de mecanismos de flexibilização, de forma a facilitar o atendimento aos compromissos assumidos por esses países. Entre esses mecanismos, destaca-se o Mecanismo de Desenvolvimento Limpo (MDL), que permite aos países desenvolvidos compensarem suas emissões, por meio de financiamentos de projetos ambientais sediados em países em desenvolvimento.

Uma das linhas de projetos consideradas elegíveis no MDL é o resgate de emissões e fixação de carbono através de atividades de florestamento e reflorestamento, denominados projetos de "seqüestro" de carbono. Esse tipo de projeto se enquadra na categoria de Agricultura, Floresta e Outros Usos da Terra (AFOLU), do Protocolo de Kyoto.

No primeiro período de compromisso (2008-2012), o total de redução de emissões resultantes de atividades de AFOLU não poderá ultrapassar $1 \%$ do total das emissões do ano-base de cada Parte Integrante do Anexo I, multiplicado por 5 (MARECHAL e HECQ, 2005). E, ainda, essas atividades podem ser empregadas somente em terras que, em 31/12/89, não continham florestas.

Uma vez comprovada a efetiva redução de emissão de GEEs ou o aumento da fixação de carbono na vegetação, os participantes do projeto poderão auferir Certificados de Emissões Reduzidas - CERs.

Os dados utilizados para a avaliação do estoque de carbono referem-se à biomassa das árvores em seus diversos componentes (tronco, galhos, folhas, raízes), por se constituírem em grandes reservas de carbono por unidade de área (REIS et al., 1994).
Diferentes tipos de florestas armazenam diversas quantidades de carbono em sua biomassa, e locais diferentes dentro do mesmo tipo de floresta também faz variar a quantidade de biomassa (HOUGHTON, 1994). Essa variação pode ser atribuída às características inerentes da planta, aos fatores ambientais, às condições edafoclimáticas e às práticas de manejo adotadas (WANG e FENG, 1995; ALBRECHT e KANDJI, 2003).

O "seqüestro" de carbono por espécies florestais de ciclo longo, cuja exploração econômica não está voltada aos produtos madeireiros, a exemplo do cacau e da seringueira, apresenta vantagens comparativas em relação às espécies de ciclo curto e que são plantadas com a finalidade de explorar a sua madeira. Além de estocar o carbono por um período de tempo maior, quando o plantio é realizado com a finalidade nãomadeireira, supõe-se que o carbono ficará estocado por mais tempo na vegetação. Fung (2000) apud Pandey (2002) ressaltou que o tempo da retenção do carbono na árvore é uma consideração importante para projetos candidatos à geração de créditos de carbono. Esse mesmo autor afirmou que, além de remover o dióxido de carbono da atmosfera e armazenar o carbono, os sistemas consorciados possuem fortes contribuições para o desenvolvimento sustentável.

Segundo Wise e Cacho (2005), projetos agroflorestais são atividades capazes de seqüestrar e armazenar carbono, podendo emitir CERs para serem negociados no mercado de créditos de carbono. Para Noble (2003) apud Wise e Cacho (2005), os sistemas agroflorestais têm potencial para capturar aproximadamente $400 \mathrm{Mt} \mathrm{C}$ por ano.

Nesse contexto, as atividades de florestamento e reflorestamento envolvendo o consórcio seringueiracacau surgem como uma possibilidade de projeto a pleitear créditos de carbono através do MDL. Tanto a seringueira quanto o cacaueiro apresentam vantagens consideráveis quanto ao armazenamento de carbono, visto que ambos são culturas perenes e de ciclo longo, capazes de estocar o carbono em sua biomassa por um grande período de tempo. Sendo assim, para que se possa comprovar o potencial do consórcio seringueiracacau para geração de CERs, torna-se necessário conhecer a quantidade de carbono presente nesse consórcio.

Os objetivos deste estudo foram quantificar a biomassa arbórea e da serapilheira do consórcio da seringueira aos 34 anos, com o cacaueiro aos 6 anos 
de idade, e analisar o potencial dessa atividade na geração de CERs, considerando-se a possibilidade de que projetos dessa natureza possam contribuir para a redução dos gases de efeito estufa da atmosfera e vir a pleitear créditos de carbono como projetos de MDL.

\section{MATERIAL E MÉTODOS}

Este estudo foi realizado nas Fazendas Reunidas Vale do Juliana (FRVJ), localizada no Município de Igrapiúna, Bahia. As FRVJ situam-se nas coordenadas $13^{\circ} 50^{\prime} 46^{\prime \prime}$ de latitude Sul e 3950'0,85' de longitude Oeste, sendo a altitude média de 240,65 m. Segundo a classificação de Köeppen, o clima na região encontrase na faixa Af, sendo caracterizado como quente e úmido, sem estação seca definida. A temperatura média anual varia entre $23^{\circ}$ e $25^{\circ} \mathrm{C}$, e a umidade relativa do ar é superior a $80 \%$. Os solos da região são classificados como Latossolos Vermelho-Amarelos Distróficos de textura argilosa (EMBRAPA, 2006).

A coleta dos dados para a quantificação da biomassa vegetal foi realizada em uma área de 2,2 ha de plantio de seringueiras com 34 anos de idade, em espaçamento de 7 × $3 \mathrm{~m}$, consorciada com cacaueiros enxertados, de 6 anos de idade, plantados no espaçamento de 3 x $3 \mathrm{~m}$.

A quantidade de carbono orgânico do solo nos primeiros $30 \mathrm{~cm}$ de profundidade, na época da realização do experimento, era de: $67,2 \mathrm{~g} \mathrm{~kg}^{-1}$ na camada de $0-10$ $\mathrm{cm} ; 38,0 \mathrm{~g} \mathrm{~kg}^{-1}$ na camada de $10-20 \mathrm{~cm}$; e $30,4 \mathrm{~g} \mathrm{~kg}^{-1}$ na camada de 20-30 cm. Na profundidade de $1 \mathrm{~m}$, o teor de matéria orgânica foi de $14 \mathrm{~g} \mathrm{~kg}^{-1}$.

O procedimento adotado para a escolha da árvoremodelo foi baseado no estudo de Soares (1995) e Soares et al. (1996). Inicialmente, procurou-se conhecer a distribuição diamétrica das árvores do consórcio. Para isso, procedeu-se à medição do diâmetro com casca, à altura do peito-DAP $(1,30 \mathrm{~m})$ das árvores de seringueira, e do diâmetro com casca, à altura de inserção do primeiro galho dos cacaueiros. Em seguida, foi calculado o diâmetro médio (q) das populações de seringueira e de cacaueiros, por meio da seguinte expressão, utilizada por Campos e Leite (2002):

$$
q=\sqrt{\frac{\sum d^{2}}{n}}
$$

em que: q = diâmetro médio ou quadrático, em cm; d = diâmetro de cada árvore, em cm; e n = número de árvores ou frequiência.

Com base nos diâmetros médios, foram selecionadas cinco seringueiras e 10 cacaueiros como árvores-amostra, para quantificação da biomassa dos componentes da parte aérea (tronco, folhas e galhos) e do sistema radicular (raiz pivotante e raízes laterais).

A determinação da biomassa foi feita utilizandose os métodos direto e destrutivo de árvores (TEIXEIRA et al., 1994; TEIXEIRA e OLIVEIRA, 1999; SANQUETA, 2002; CARMO et al., 2004).

Uma vez derrubada cada árvore-amostra de seringueira e de cacau, elas foram desfolhadas e suas folhas, ensacadas e pesadas. Em seguida, foi retirada e pesada uma amostra representativa do material para determinação da massa de matéria seca.

Depois de desfolhada, cada árvore de seringueira e de cacau foi desgalhada, sendo seus galhos separados e pesados. Para maior detalhamento da biomassa e do carbono, os galhos foram divididos em três classes, de acordo com as dimensões desse componente nas árvores de seringueira e cacau. Assim, os galhos da seringueira foram separados obedecendo à seguinte classificação diamétrica: galhos grossos $(>10 \mathrm{~cm})$, galhos médios (entre 5 e $10 \mathrm{~cm})$ e galhos finos $(<5 \mathrm{~cm})$. Com relação aos galhos de cacau, procedeu-se da mesma forma, sendo a classificação diamétrica a seguinte: galhos grossos (> 2,3 cm), galhos médios (entre 1,3 e 2,3 cm) e galhos finos $(<1,3 \mathrm{~cm})$. Após a pesagem dos galhos da seringueira e do cacau, foram retiradas e pesadas amostras úmidas representativas de cada classe diamétrica para determinação da massa de matéria seca.

$\mathrm{O}$ tronco da seringueira foi seccionado e pesado para quantificação da biomassa. Dele foi retirada e pesada uma amostra formada por três discos de aproximadamente $2,5 \mathrm{~cm}$ de espessura, correspondentes à altura de 0,5 $\mathrm{m}$ do solo, ao DAP e à altura da inserção do primeiro galho. O tronco do cacau foi pesado inteiro e dele retirada uma amostra em forma de disco de aproximadamente $2,5 \mathrm{~cm}$ de espessura, correspondente ao meio, baseandose em estudo de Soares (1995), Soares et al. (1996) e Oliveira Neto et al. (2003).

A quantificação da biomassa das raízes laterais da seringueira e do cacau foi realizada pelo método de abertura de trincheiras, proposto por Carmo et al. (2004), nas cinco

R. Árvore, Viçosa-MG, v.32, n.6, p.969-978, 2008 
árvores de seringueira, de modo que fossem coletadas raízes de seringueira e de cacau ao mesmo tempo. Para isso, foi escavada uma trincheira de $1,5 \mathrm{~m}$ de comprimento entre árvores e outra de 3,5 m de comprimento entre as linhas de plantio da seringueira, ambas com 0,6 m de largura e 0,6 $\mathrm{m}$ de profundidade, totalizando uma área de $3 \mathrm{~m}^{2}$ para cada árvore $(1,5 \mathrm{~m}$ x 0,6 $\mathrm{m}+3,5 \mathrm{~m}$ $\left.\mathrm{x} 0,6 \mathrm{~m}=3 \mathrm{~m}^{2}\right)$. Inicialmente, foram retiradas e separadas todas as raízes de seringueira e de cacau dos primeiros $30 \mathrm{~cm}$ e, depois, as dos próximos $30 \mathrm{~cm}$. As raízes foram separadas e pesadas segundo a classificação diamétrica: no caso da seringueira, raízes grossas $(>5 \mathrm{~cm})$, raízes médias (entre 1,5 e $5 \mathrm{~cm}$ ) e raízes finas $(<1,5 \mathrm{~cm})$; com relação ao cacau, raízes grossas $(>1,5 \mathrm{~cm})$, raízes médias (entre 0,65 e 1,5 cm) e raízes finas $(<0,65 \mathrm{~cm}$ ). Após a separação e a pesagem, foram retiradas amostras úmidas representativas de cada classe diamétrica das raízes, para determinação da massa de matéria seca.

No caso da raiz pivotante da seringueira, foi escavada uma trincheira com profundidade de aproximadamente $2,0 \mathrm{~m}$ e retirada a raiz pivotante até aquela profundidade, a qual foi, em seguida, seccionada e pesada. Após a pesagem, foi coletada e pesada uma amostra formada por discos de aproximadamente 2,5 $\mathrm{cm}$ de espessura, correspondentes ao meio e às extremidades da raiz. A raiz do cacau foi escavada, retirada inteira do solo e pesada, sendo dela coletada uma amostra formada por discos de cerca de 2,5 $\mathrm{cm}$ de espessura do meio e das extremidades, para determinação da massa de matéria seca.

A biomassa da serapilheira foi quantificada através de uma coleta única do material na superfície do solo, segundo procedimentos propostos por Sanqueta (2002). Para isso, utilizou-se um quadrado de área interna de $0,25 \mathrm{~m}^{2}$, disposto nos seguintes pontos: $0,75 \mathrm{~m}$ e 1,5 $\mathrm{m}$ distanciados da seringueira entre plantas e $0,5 \mathrm{~m}$, 2,0 m e 3,5 m distanciados da seringueira entre as linhas de plantio, num total 10 pontos por árvore, correspondendo a uma área de $2,5 \mathrm{~m}^{2}$. Depois de coletadas as amostras da serapilheira, o material foi misturado e pesado. Em seguida, foram retiradas e pesadas subamostras desse material.

Depois de coletadas e pesadas, as amostras úmidas de todos os compartimentos das árvores de seringueira, de cacau e da serapilheira, foram levadas para o laboratório e colocadas em estufa de circulação forçada de ar, a uma temperatura de aproximadamente $75^{\circ} \mathrm{C}$, até a estabilização da massa de matéria seca.

R. Árvore, Viçosa-MG, v.32, n.6, p.969-978, 2008
De posse da massa de matéria úmida de cada compartimento das árvores, da serapilheira e da massa de matéria úmida e seca das amostras, a biomassa seca das árvores e da serapilheira foi determinada através do método da proporcionalidade utilizado por Teixeira et al. (1994), Soares et al. (1996), Teixeira e Oliveira (1999) e Carmo et al. (2004). Para isso, empregou-se a seguinte fórmula:

$$
M S(C)=\frac{M U(c) * M S(a)}{M U(a)}
$$

em que:

$\operatorname{MS}(C)=$ massa de matéria seca total no campo, em kg; MS(a) = massa de matéria seca das amostras, em kg; MU(a) = massa de matéria úmida das amostras, em kg; e MU(c) = massa de matéria úmida total no campo, em kg.

Por meio da soma das médias da biomassa seca dos compartimentos das árvores, obteve-se a biomassa total de uma seringueira e de um cacaueiro. Em seguida, esse valor foi extrapolado para $1 \mathrm{ha}$, considerandose uma densidade de 476 seringueiras e 1.111 cacaueiros por hectare. A biomassa média da serapilheira encontrada na área de 2,5 $\mathrm{m}^{2}$ também foi extrapolada para cada hectare. Assim, a biomassa seca total em 1 ha do consórcio foi determinada através da soma da biomassa seca das árvores e da biomassa seca da serapilheira.

A estimativa do estoque de carbono na biomassa arbórea e na serapilheira foi feita, considerando-se que $50 \%$ da matéria seca seja carbono, valor sugerido por Dewar e Cannel (1992), Soares e Oliveira (2002) e Losi et al. (2003).

Obtidas as estimativas de carbono nas árvores e na serapilheira, contabilizaram-se os CERs, por meio da conversão do carbono em $\mathrm{CO}_{2}$ equivalente $\left(\mathrm{CO}_{2 \mathrm{eq}}\right)$. Essa conversão foi feita, multiplicando-se o total de carbono por 44/12 (razão do peso molecular do $\mathrm{CO}_{2}$ e do carbono), ou seja, uma tonelada de carbono corresponde a 3,67 toneladas de $\mathrm{CO}_{2 \mathrm{eq}}$. (IPCC, 2006). Dessa forma, os CERs gerados pelo consórcio corresponderão à quantidade de $\mathrm{CO}_{2 \text { eq. }}$ estocada na biomassa arbórea da seringueira e do cacaueiro e na biomassa da serapilheira. Apesar de não ser objetivo deste estudo e, também, não se ter acompanhamento da variação no estoque de carbono orgânico no solo desde a implantação das culturas, é importante que 
em projetos que objetivem a geração de créditos de carbono se faça o monitoramento desse compartimento. Assim, caso o estoque aumente ou diminua, a diferença deverá ser considerada nos cálculos, somando-se ou subtraindo do total de carbono.

\section{RESULTADOS E DISCUSSÃO}

\subsection{Caracterização diamétrica do consórcio seringueira-cacau}

As distribuições diamétricas das populações de seringueira e de cacau apresentaram tendência característica de povoamentos eqüiâneos, ou seja, tendência à normalidade, com maior freqüência de árvores com diâmetro próximo ao valor médio (Figuras $1 \mathrm{AB}$ ). A maior amplitude de diâmetros foi verificada na população de seringueira, uma vez que as árvores são mais velhas (34 anos) do que as árvores de cacau (seis anos).

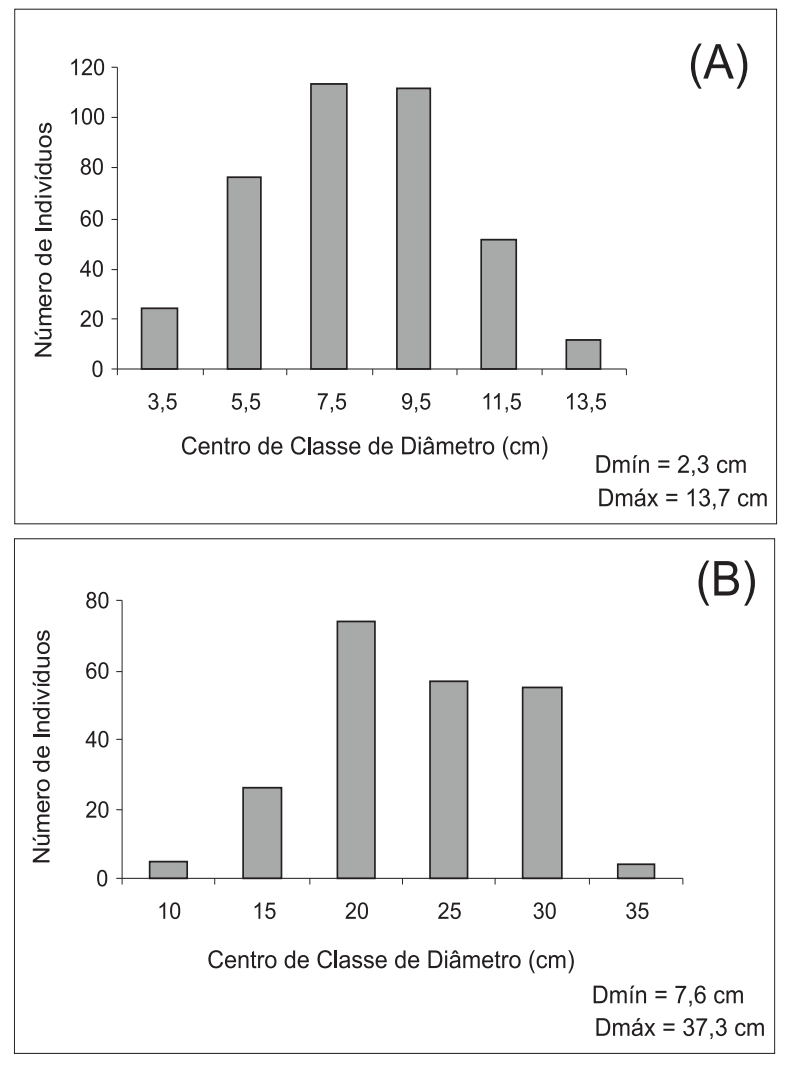

Figuras 1 - Número de indivíduos da população de seringueira (a) e de cacau (b) por classe de diâmetro.

Figure 1)-Number of individuals of the population of rubber tree (a) and cocoa tree (b) for diameter classroom.

\subsection{Estoque de biomassa e de carbono no consórcio}

Analisando a média da massa de matéria úmida e de matéria seca das árvores de seringueira e de cacau e sua distribuição nos diferentes compartimentos (Quadro1), verificou-se que 52\% da massa da seringueira era água. Por sua vez, a massa de matéria seca da parte aérea e das raízes correspondeu a $49 \%$ e $44 \%$ da massa úmida, respectivamente. A massa de matéria seca do cacaueiro foi equivalente a $33 \%$ de sua massa úmida. A massa de matéria seca da parte aérea e das raízes do cacaueiro representou $34 \%$ e $30 \%$ de sua massa de matéria úmida, respectivamente.

Considerando 1 ha do consórcio, estimou-se um estoque de carbono arbóreo de $89,9 \mathrm{Mg} \mathrm{C} \mathrm{ha}^{-1}$, estando $84,7 \mathrm{Mg} \mathrm{Cha}^{-1}$ armazenadas nas árvores de seringueira e 5,22 $\mathrm{Mg} \mathrm{C}^{-1}$ nos cacaueiros (Quadro 2). Fernandes et al. (2007) encontraram, em um povoamento de seringueira com 12 anos de idade, em Minas Gerais, 62,7 Mg C ha-1. Rahaman e Sivakumaran (1998), em estudo realizado em Bali, Indonésia, obtiveram 92,8 $\mathrm{Mg} \mathrm{C} \mathrm{ha}^{-1}$ em povoamento de seringueira ao final de 30 anos. Verificou-se, assim, que este estudo encontrou valores de estoque de carbono bem próximos aos de outros trabalhos.

Conforme demonstrado no Quadro 2, a maior quantidade do carbono da seringueira estava estocada na parte aérea, representando $81 \%$ do carbono total, e os outros $19 \%$ encontraram-se estocados nas raízes.

Em relação apenas à parte aérea, $72 \%$ do carbono estava estocado na copa e $28 \%$ no tronco. Esses resultados estão próximos àqueles encontrados por Carmo et al. (2003). Nesse estudo, os autores verificaram que em plantios de seringueira, aos 15 anos de idade, $78 \%$ do carbono da parte aérea estava estocado na copa da árvore e os outros $22 \%$, no tronco.

No que se refere ao cacau, o maior porcentual de carbono também foi encontrado na parte aérea, representando $72 \%$ do carbono total. Com relação ao carbono das raízes, $12 \%$ correspondeu à raiz pivotante e $16 \%$, às raízes laterais.

Durante a fase inicial de desenvolvimento de uma floresta, grande parte dos carboidratos é direcionada para a produção da copa e das raízes. Com o passar do tempo, a produção de biomassa do tronco aumenta e a da copa diminui gradualmente (SCHUMACHER, 1996). No entanto, o maior porcentual de carbono da

R. Árvore, Viçosa-MG, v.32, n.6, p.969-978, 2008 
seringueira deveria estar armazenado no tronco, mas ele foi encontrado nos galhos. Isso pode ser justificado pela idade do plantio, pelo espaçamento adotado e pelas práticas silviculturais dispensadas à seringueira, já que essas práticas são aplicadas, buscando-se maior produção de galhos e folhas para que haja maior área fotossintética e maior produção de látex. Além disso, durante a queda das folhas há redução no crescimento do tronco, uma vez que, com a emissão de novos folíolos, os fotoassimilados são direcionados para a formação de área foliar. Já com relação ao cacau aos 6 anos de idade, observou-se o esperado: como o plantio ainda é novo, a maior parte do carbono encontrava-se estocada na copa.

Quadro 1 - Massa média de matéria úmida e de matéria seca dos compartimentos das árvores de seringueira e de cacau Table 1-Average weight of humid and dry substance of the compartments of rubber tree and cocoa tree

\begin{tabular}{|c|c|c|c|c|}
\hline \multirow[b]{2}{*}{$\begin{array}{l}\text { Compartimento } \\
\text { da árvore }\end{array}$} & \multicolumn{2}{|c|}{ Seringueira } & \multicolumn{2}{|c|}{ Cacau } \\
\hline & $\begin{array}{l}\text { Massa de matéria } \\
\text { úmida (kg/árvore) }\end{array}$ & $\begin{array}{c}\text { Massa de matéria } \\
\text { seca (kg/árvore) }\end{array}$ & $\begin{array}{l}\text { Massa de matéria } \\
\text { úmida ( } \mathrm{kg} \text { /árvore) }\end{array}$ & $\begin{array}{c}\text { Massa de matéria } \\
\text { seca (kg/árvore) }\end{array}$ \\
\hline \multicolumn{5}{|l|}{ Parte Aérea } \\
\hline Folhas & 21,55 & 7,78 & 5,06 & 1,84 \\
\hline Tronco & 156,36 & 80,75 & 3,50 & 1,11 \\
\hline \multicolumn{5}{|l|}{ Galhos } \\
\hline Grossos & 191,36 & 96,20 & 7,26 & 2,63 \\
\hline Médios & 91,04 & 46,87 & 2,45 & 0,70 \\
\hline Finos & 129,27 & 55,86 & 1,98 & 0,51 \\
\hline Subtotal & 589,58 & 287,46 & 20,25 & 6,79 \\
\hline \multicolumn{5}{|l|}{ Raízes } \\
\hline Pivotante & 98,82 & 46,60 & 3,66 & 1,12 \\
\hline \multicolumn{5}{|l|}{ Laterais } \\
\hline Grossas & 21,84 & 9,48 & 1,35 & 0,42 \\
\hline Médias & 22,40 & 8,57 & 1,59 & 0,48 \\
\hline Finas & 11,76 & 3,59 & 1,95 & 0,57 \\
\hline Subtotal & 154,82 & 68,24 & 8,55 & 2,59 \\
\hline Massa total & 744,40 & 355,70 & 28,80 & 9,38 \\
\hline
\end{tabular}

Quadro 2 - Estoque médio e porcentual de carbono nos compartimentos da seringueira e do cacaueiro por hectare Table 2 - Average carbon storage and percentage in the compartments of rubber tree and cocoa tree for hectare

\begin{tabular}{|c|c|c|c|c|}
\hline \multirow[b]{2}{*}{$\begin{array}{c}\text { Compartimento } \\
\text { da árvore }\end{array}$} & \multicolumn{2}{|c|}{ Seringueira } & \multicolumn{2}{|c|}{ Cacau } \\
\hline & $\begin{array}{c}\text { Carbono } \\
\left(\mathrm{Mg} \mathrm{C} \mathrm{ha}^{-1}\right)\end{array}$ & $\begin{array}{c}\text { Valor } \\
\text { Porcentual (\%) } \\
\end{array}$ & $\begin{array}{c}\text { Carbono } \\
\left(\mathrm{Mg} \mathrm{C} \mathrm{ha}^{-1}\right)\end{array}$ & $\begin{array}{c}\text { Valor } \\
\text { Porcentual }(\%) \\
\end{array}$ \\
\hline \multicolumn{5}{|l|}{ Parte Aérea } \\
\hline Folhas & 1,85 & 2 & 1,02 & 20 \\
\hline Tronco & 19,22 & 23 & 0,62 & 12 \\
\hline \multicolumn{5}{|l|}{ Galhos } \\
\hline Grossos & 22,89 & 27 & 1,46 & 28 \\
\hline Médios & 11,15 & 13 & 0,39 & 7 \\
\hline Finos & 13,30 & 16 & 0,28 & 5 \\
\hline Subtotal & 68,41 & 81 & 3,77 & 72 \\
\hline \multicolumn{5}{|l|}{ Raízes } \\
\hline Pivotante & 11,09 & 13 & 0,62 & 12 \\
\hline \multicolumn{5}{|l|}{ Laterais } \\
\hline Grossas & 2,25 & 3 & 0,24 & 5 \\
\hline Médias & 2,04 & 2 & 0,27 & 5 \\
\hline Finas & 0,86 & 1 & 0,32 & 6 \\
\hline Subtotal & 16,24 & 19 & 1,45 & 28 \\
\hline Total & 84,65 & 100 & 5,22 & 100 \\
\hline
\end{tabular}


A seqüência na ordem de distribuição do carbono na seringueira (copa-tronco-raízes) em estudo é semelhante à de um consórcio com 15 anos de idade, registrada por Teixeira et al. (1994). No consórcio aos 15 anos de idade, o porcentual de carbono na seringueira foi maior nas folhas e nos galhos e menor nos tronco e raízes, em relação aos 34 anos.

No cacau, o estoque de carbono estimado por Teixeira et al. (1994) foi maior na copa (66\%), seguido pelas raízes $(18 \%)$ e pelo tronco $(16 \%)$, sequiência semelhante à observada neste trabalho. No cacaueiro com 15 anos de idade, verificou-se menor porcentual de carbono nas folhas e maior no tronco, em relação ao cacaueiro com 6 anos de idade. Outro fato foi que o porcentual de carbono nas raízes do cacaueiro com 15 anos foi menor do que o encontrado no cacaueiro com 6 anos, comprovando que nos primeiros anos ocorre maior acúmulo de carbono nas raízes. Tanto na seringueira quanto no cacaueiro, pode-se inferir que as diferenças observadas na distribuição do carbono nos compartimentos das árvores estão relacionadas à idade, visto que a tendência é de que o porcentual de biomassa das folhas e dos galhos diminua e o do tronco aumente à medida que também aumenta a idade do plantio.

Essa tendência na distribuição de biomassa (ou carbono) nas espécies florestais de acordo com a idade do plantio também foi verificada por Ladeira et al. (2001) nas diferentes espécies do gênero Eucalyptus. Neste estudo, os referidos autores observaram que aos 15 meses a proporção média de biomassa da copa era de 40,4\%, mas, aos 84 meses, passou a ser apenas de $11,4 \%$. Quanto ao tronco, aos 15 meses a biomassa estocada correspondeu a $19,4 \%$, e aos 84 meses a proporção desse compartimento aumentou para $60,4 \%$ da biomassa total.

Considerando a estimativa do estoque de carbono da seringueira e do cacaueiro, 84,7 $\mathrm{Mg} \mathrm{C}^{-1}$ e 5,22 $\mathrm{Mg} \mathrm{C} \mathrm{ha-1,} \mathrm{respectivamente,} \mathrm{pode} \mathrm{se} \mathrm{dizer} \mathrm{que} \mathrm{o}$ incremento médio anual de carbono da seringueira foi de 2,5 $\mathrm{Mg} \mathrm{C}^{-1}$ ano e do cacaueiro, $0,87 \mathrm{Mg} \mathrm{C}^{-}$ ${ }^{1}$ ano. Esses valores, quando comparados com os de espécies florestais do gênero Eucalyptus $(11,8 \mathrm{Mg}$ $\mathrm{C}^{-1}$ ano) e Pinnus (6,7 $\mathrm{Mg} \mathrm{C}^{-1}$ ano), obtidos em estudos realizados por Paixão et al. (2006) e Schumacher et al. (2002), respectivamente, evidenciaram que a seringueira e o cacaueiro apresentam incrementos anuais de carbono inferiores. Entretanto, deve-se levar em consideração o ciclo da cultura, o que determina o tempo de estocagem do carbono no plantio. Tanto a seringueira quanto o cacaueiro são espécies de ciclo longo, capazes de armazenar o carbono por longo tempo, além de produzirem economicamente por mais de 30 anos. Além disso, a exploração econômica da seringueira e do cacaueiro não implica, necessariamente, o corte da árvore, o que evita o possível retorno do carbono para a atmosfera.

O estoque de biomassa seca e de carbono encontrado na serapilheira, na época da realização do experimento, foi 3,35 $\mathrm{Mg} \mathrm{C}^{-1} \mathrm{e} 1,67 \mathrm{Mg} \mathrm{C} \mathrm{ha}^{-1}$, respectivamente. Ao analisar o material coletado na superfície do solo, observou-se que ele era constituído de galhos, folhas, raízes e material reprodutivo (sementes, flores). O estoque de carbono da serapilheira foi relativo a $2,5 \%$ do carbono da copa da seringueira e a $44 \%$ do carbono da copa do cacau. A diferença entre o porcentual de carbono da serapilheira em relação ao da copa da seringueira e ao da copa do cacau pode ser atribuída às características das espécies (tamanho da copa, formação de galhos, quantidade de folhas), à época de realização do experimento e às práticas silviculturais aplicadas. A quantidade de resíduos orgânicos na superfície do solo e, conseqüentemente, o estoque de carbono da serapilheira dependem da queda do material e de sua velocidade de decomposição. Em áreas cultivadas com o consórcio seringueira-cacau, a deposição de resíduos sobre o solo é maior na época de desfolha da seringueira e quando são efetuadas as podas do cacaueiro.

Foram estocadas no consórcio da seringueira aos 34 anos com o cacaueiro aos 6 anos de idade $336 \mathrm{Mg}$ $\mathrm{CO}_{\text {2eq. }}$ ha $^{-1}$, o que corresponde à geração de $336 \mathrm{CERs}$ $h^{-1}$. Com relação à contribuição das culturas na capacidade de estocagem de $\mathrm{CO}_{2 \text { eq. }}$, pode-se inferir que a seringueira aos 34 anos se encontrava em estágio de estabilização de crescimento e o cacaueiro aos 6 anos de idade, em fase de desenvolvimento. Dessa forma, prevê-se o aumento no estoque de carbono do consórcio e, consequientemente, no número de CERs, que serão oriundos, particularmente, da cultura do cacau.

Considerando o período de creditação definido nas Modalidades e Procedimentos dos Projetos de MDL (30 anos, sem direito a renovação; ou 20 anos, renovável por duas vezes), pode-se dizer que o consórcio é uma alternativa viável de projeto, em termos de tempo de estocagem do carbono. Pois, conforme mencionado, a exploração econômica tanto da seringueira quanto do cacau se estende por mais de 30 anos.

R. Árvore, Viçosa-MG, v.32, n.6, p.969-978, 2008 


\subsection{O consórcio seringueira-cacau no contexto das mudanças climáticas}

Do ponto de vista climático, o plantio do consórcio seringueira-cacau implicará a retirada de $\mathrm{CO}_{2}$ da atmosfera, contribuindo para a mitigação do efeito estufa. Além de atender à principal premissa dos projetos de carbono, a de reduzir o $\mathrm{CO}_{2}$ da atmosfera, o consórcio seringueira-cacau possui algumas características que o torna capaz de atender a um dos objetivos do MDL: contribuir para o desenvolvimento sustentável do país de implantação. Entre essas características, destacam-se o uso intensivo de mão-de-obra, que contribui significativamente para a geração de emprego e de renda no campo; o melhor aproveitamento da área de plantio, pois as entrelinhas das seringueiras permitem a consorciação de culturas intercalares; a possibilidade de obtenção de receitas praticamente durante todos os meses do ano; e o melhor aproveitamento dos recursos naturais. Vale ressaltar que cabe ao país hospedeiro do projeto definir seu conceito de sustentabilidade e confirmar se uma atividade de projeto contribui ou não para isso.

A possibilidade de agregação dos CERs ao consórcio surge como um atrativo ao retorno tanto da cultura do cacau quanto da seringueira, tendo em vista que fatores como a incidência de doenças, a queda nos preços e a baixa produtividade, os quais afetam ambas as culturas, têm ocasionado grande desestímulo por parte dos produtores e conseqüentes abandonos das áreas plantadas. $\mathrm{O}$ incentivo a essa atividade poderá trazer, além de vantagens econômicas para o Brasil, benefícios ambientais.

Os projetos de MDL de florestamento e reflorestamento têm encontrado maiores dificuldades para serem registrados e para emitirem os CERs. Essa dificuldade está associada às incertezas quanto à durabilidade e aos riscos de reversibilidade dessa atividade. É alegado que os projetos florestais não oferecem segurança de perenidade por estarem sujeitos à ocorrência de sinistros (fogo e pragas) ou à substituição por outro tipo de ocupação do solo. No entanto, é necessário que haja maior empenho na comprovação do potencial desses projetos no armazenamento do carbono e na emissão de CERs.
O Brasil, além de ser o berço da seringueira e do cacau, apresenta características altamente favoráveis à geração de projetos florestais candidatos ao recebimento de CERs. A disponibilidade de terras e de mão-de-obra, as condições edafoclimáticas e o domínio de tecnologia são fatores que permitem ao país captar recursos com o MDL e contribuir significativamente para a mitigação do efeito-estufa. O consórcio seringueira-cacau pode contribuir para a redução do $\mathrm{CO}_{2}$ da atmosfera e, paralelamente, possui potencial para geração de CERs para serem negociados entre os países desenvolvidos (Anexo I) e aqueles em desenvolvimento, entre eles o Brasil.

\section{CONCLUSÕES}

De acordo com os resultados pode-se concluir que:

- O estoque de carbono na biomassa arbórea, particularmente das árvores de seringueira, credencia o consórcio seringueira-cacau como atividade promissora na geração de Certificados de Emissões Reduzidas.

- Tanto a seringueira quanto o cacaueiro são espécies recomendáveis para serem utilizadas em plantios florestais para a geração de créditos de carbono, pois são de ciclo longo, cuja exploração econômica está relacionada, principalmente, aos produtos não madeireiros.

- Embora o cacaueiro apresente baixo estoque de carbono quando comparado com árvores de seringueira, a cultura é importante para a consorciação, tendo em vista os aspectos econômicos e sociais.

- A possibilidade de agregar créditos de carbono ao cultivo do consórcio atua como atrativo ao plantio de ambas as culturas.

- O consórcio é importante para o resgate de $\mathrm{CO}_{2}$ da atmosfera e, conseqüentemente, contribui para a mitigação do aquecimento global.

\section{AGRADECIMENTOS}

À Comissão Executiva do Plano da Lavoura Cacaueira - CEPLAC, pela concessão dos dados e pelo apoio ao projeto; ao Sr. Norberto Odebrecht, pelo apoio técnico e por disponibilizar as Fazendas Reunidas Vale do Juliana, para a execução do experimento; e ao Conselho Nacional de Desenvolvimento Científico e Tecnológico (CNPq), pela bolsa de estudo e de produtividade em pesquisa. 


\section{REFERÊNCIAS}

ALBRECHT, A.; KANDJI, S. T. Carbon sequestration in tropical agroforestry systems. Agriculture, Ecosystems and Environment, v.99, n.1, p.15-27, 2003.

APPS, M. J. et al. Carbon budget of the Canadian forest product sector. Environment Science \& Policy, v.2, n.1, p.25-41, 1999.

CAMPOS, J. C. C.; LEITE, H. G. Mensuração florestal: perguntas e respostas. Viçosa, MG: Universidade Federal de Viçosa, 2002. 407p.

CARMO, C. A. F. S. et al. Estimativa do estoque de carbono na biomassa de clones de seringueira em solos da Zona da Mata/MG. Rio de Janeiro: Embrapa Solos, 2004. 14p.

CARMO, C. A. F. S. et al. Estimativa do estoque de carbono na biomassa do clone de seringueira RRIM 600 em solos da Zona da Mata mineira. Rio de Janeiro: Embrapa Solos, 2003. 19p. (Boletim de Pesquisa e Desenvolvimento, 28).

DEWAR, R. C.; CANNELL, M. G. R. Carbon sequestration in the trees, products and soils of forest plantations: an analysis using UK examples. Tree Physiology, v.11, n.1, p.49-71, 1992.

EMPRESA BRASILEIRA DE PESQUISA AGROPECUÁRIA - EMBRAPA. Centro Nacional de Pesquisa de Solos. Sistema brasileiro de classificação de solos. 2.ed. Rio de Janeiro: Embrapa Solos, 2006. 306p.

FERNANDES, T. J. G. et al. Quantificação do carbono estocado na parte aérea e raízes de Hevea sp., aos 12 anos de idade, na Zona da Mata Mineira. Revista Árvore, v.31, n.4, p.657-665, 2007.

HOUGHTON, R. A. As florestas e o ciclo de carbono global: Armazenamento e emissões atuais. In: SEMINÁRIO EMISS ÃO X “SEQÜESTRO" DE CO2: UMA OPORTUNIDADE DE NEGÓCIOS PARA O BRASIL, 1994, Rio de Janeiro. Anais... Rio de Janeiro: CVRD, 1994. p.40-75.
INTERGOVERNMENTAL PANEL ON CLIMATE CHANGE - IPCC. 2006 IPCC Guidelines for National Greenhouse Gas Inventories: Agriculture, forestry and other land use. Japan: Institute for Global Environmental Strategies (IGES), 2006.v.4.

LADEIRA, B. R. et al. Produção de biomassa de Eucalipto sob três espaçamentos, em uma seqüência de idade. Revista Árvore, v.25, n.1, p.69-78, 2001.

LOSI, C. J. et al. Analysis of alternative methods for estimating carbon stock in young tropical plantations. Forest Ecology and Management, v.184, n.1/3, p.355-368, 2003.

MARÉCHAL, K.; HECQ, W. Temporary credits: A solution to the potential non-permanence of carbon sequestration in forests? Ecological Economics, v.58, n.4, p.699-716, 2006.

OLIVEIRA NETO, S. N. et al. Produção e distribuição de biomassa em Eucalyptus camaldulensis Dehn. em resposta à adubação e ao espaçamento. Revista Árvore, v.27, n.1, p.15-23, 2003.

PAIXÃO, F. A. et al. Quantificação do estoque de carbono e avaliação econômica de diferentes alternativas de manejo em um plantio de eucalipto. Revista Árvore, v.30, n.3, p.411-420, 2006.

PANDEY, D. N. Carbon sequestration in agroforestry systems. Climate Policy, v.2, n.4, p.367-377, 2002.

RAHAMAN, W. A.; SIVAKUMARAN, S. Studies of carbon sequestration in rubber. UNCTAD/IRSG RUBBER FORUM, 1998, Bali. Paper...Bali:1998.

REIS, M. G. F. et al. "Seqüestro" e armazenamento de carbono em florestas nativas e plantadas nos estados de Minas Gerais e Espírito Santo. In: SEMINÁRIO EMISSÃO X “SEQÜESTRO” $\mathrm{DE} \mathrm{CO}_{2}$ : uma oportunidade de negócios para o Brasil, 1994, Rio de Janeiro. Anais... Rio de Janeiro: CVRD, 1994. p.155-195.

SANQUETA, C. R. Métodos de determinação de biomassa florestal. In: SANQUETTA, C. R. et al. (Eds.). As florestas e o carbono. Curitiba: Universidade Federal do Paraná, 2002. p.119-140.

R. Árvore, Viçosa-MG, v.32, n.6, p.969-978, 2008 
SCHUMACHER, M. V. Ciclagem de nutrientes como base da produção sustentada em ecossistemas florestais. In: SIMPÓSIO SOBRE ECOSSISTEMAS NATURAIS DO MERCOSUL: O AMBIENTE DA FLORESTA, 1., 1996, Santa Maria. Anais... Santa Maria: UFSM/CEPEF, 1996. p.65-77.

SCHUMACHER, M. V. et al. Estoque de carbono em florestas de Pinus taeda L. e Acácia mearnsii de Wild. plantadas no estado do Rio Grande do Sul. In: SANQUETTA, C. R. et al. (Eds.). As florestas e o carbono. Curitiba: Universidade Federal do Paraná, 2002. p.141-152.

SOARES C. P. B. Modelos para estimar a biomassa da parte aérea de um povoamento de Eucaliptus grandis, na região de Viçosa, Minas Gerais. 1995. 86f. Dissertação (Mestrado em Ciência Florestal) Universidade Federal de Viçosa, Viçosa, MG, 1995.

SOARES, C. P. B. et al. Modelos para estimar a biomassa da parte aérea em um povoamento de Eucalyptus grandis na região de Viçosa, Minas Gerais. Revista Árvore, v.20, n.2, p.179-189, 1996.
SOARES, C. P. B.; OLIVEIRA, M. L. R.

Equações para estimar a quantidade de carbono na parte aérea de árvores de eucalipto em Viçosa, Minas Gerais. Revista Árvore, v.2/6, n.5, p.533-539, 2002.

TEIXEIRA, L. B.; BASTOS, J. B.; OLIVEIRA, R. F. Biomassa vegetal em agroecossistemas de seringueira consorciada com cacaueiro no Nordeste Paraense. Belém: Embrapa CPATU, 1994. 15p. (Boletim de Pesquisa, 153).

TEIXEIRA, L. B.; OLIVEIRA, R. F. Biomassa vegetal e carbono orgânico em capoeiras e agroecossistemas no Nordeste do Pará. Belém: Embrapa Amazônia Oriental, 1999. 21p. (Boletim de Pesquisa)

WANG, X.; FENG, Z. Atmospheric carbon sequestration through agroforestry in China. Energy, v.20, n.2, p.117-121, 1995.

WISE, R.; CACHO, O. Tree-crop interactions and their environmental and economic implications in the presence of carbon-sequestration payments. Environmental Modelling \& Software, v.20, n.9, p.1139-1148, 2005. 